\title{
MicroRNA-206 inhibits the proliferation, migration and invasion of colorectal cancer cells by regulating the c-Met/AKT/GSK-3 $\beta$ pathway
}

\author{
JIAYU LYU ${ }^{1}$, YAO SUN ${ }^{2}$, XIZHI LI ${ }^{3}$ and HUILI MA ${ }^{4}$ \\ ${ }^{1}$ Department of First General Surgery, The Fifth Hospital of Harbin, Harbin, Heilongjiang 150040; \\ ${ }^{2}$ Department of Neurology, General Hospital of Heilongjiang Province Land Reclamation Bureau, Harbin, \\ Heilongjiang 150088; ${ }^{3}$ Department of Neurology, Binzhou Medical University Hospital; ${ }^{4}$ Department of \\ Emergency Surgical Trauma Center, Binzhou Medical University Hospital, Binzhou, Shandong 256603, P.R. China
}

Received June 24, 2020; Accepted November 13, 2020

DOI: $10.3892 /$ ol.2020.12408

\begin{abstract}
An imbalance in microRNA (miRNA/miR) expression is closely associated with tumorigenesis and progression. miR-206 is downregulated in different types of tumors, including colorectal cancer (CRC). However, the effects of miR-206 on the progression of CRC, and its underlying molecular mechanisms are yet to be elucidated. The present study aimed to investigate the effects of miR-206 on the proliferation, migration and invasion of colorectal cancer cells, and determine its potential molecular mechanism. The results of the present study demonstrated that the expression levels of miR-206 and c-Met were affected in HCT116 and SW480 cells by transfected with miR-206 mimic, inhibitor or small interfering RNA-c-Met. A Dual-luciferase reporter assay was performed to identify the miRNA targets. Cell proliferation, migration and invasion assays were also performed. The results demonstrated that overexpression of miR-206 significantly decreased the viability of HCT116 and SW480 cells. The results of the Transwell assay indicated that the cell migratory and invasive abilities were inhibited following transfection with miR-206 mimic. As a target of miR-206, knockdown of c-Met significantly suppressed cell viability, migration and invasion. In addition, c-Met knockdown or overexpression of miR-206 inhibited activation of the AKT/GSK-3 $\beta$ pathway. Collectively, these results suggest that miR-206 suppresses the
\end{abstract}

Correspondence to: Mrs. Xizhi Li, Department of Neurology, Binzhou Medical University Hospital, 661 Huanghe 2nd Road, Binzhou, Shandong 256603, P.R. China

E-mail: viyligm@163.com

Mr. Huili Ma, Department of Emergency Surgical Trauma Center, Binzhou Medical University Hospital, 661 Huanghe 2nd Road, Binzhou, Shandong 256603, P.R. China

E-mail: yaig481105@sina.cn

Key words: microRNA-206, c-Met, colorectal cancer, proliferation, migration, invasion proliferation, migration and invasion of CRC cells by targeting the c-Met/AKT/GSK-3 $\beta$ pathway.

\section{Introduction}

Colorectal cancer (CRC) is the third most common malignancy among both sexes and the third leading cause of cancer-associated mortality worldwide, and the rates of incidence and mortality are 6.1 and $9.2 \%$ of the total cases in 2018 (1). Several factors, such as dysregulation of oncogenes or tumor suppressor genes, are involved in the occurrence and development of CRC, which affects the therapeutic efficacy and prognosis of CRC (2). In addition, tumor recurrence, invasion and metastasis are the main causes of mortality of patients with CRC (3). However, the underlying molecular mechanisms remain unknown.

MicroRNAs (miRNAs/miRs) belong to a family of endogenous non-coding small RNAs that usually consist of 19-24 nucleotides (4). miRNAs perform multiple functions by targeting the 3'-untranslated region (UTR) of target genes to induce transcriptional suppression or mRNA degradation (5-7). Previous studies have reported that abnormal expression of miRNAs exists in cancer tissues or cancer cell lines, which is associated with the initiation and progression of tumors, including breast cancer, bladder cancer and lung cancer (8-10). miRNAs also serve important roles in regulating tumor cell proliferation, apoptosis, migration and invasion by acting as oncogenes or tumor suppressors, or by targeting oncogenes or tumor suppressor genes $(10,11)$.

miR-206 belongs to the miR-206/133b cluster, which is responsible for the growth and development of skeletal muscle (12). Recently, miR-206 expression has been demonstrated to be downregulated in different types of human tumors, including CRC $(13,14)$, prostate $(15,16)$, lung $(17)$ and breast cancer $(17,18)$, suggesting that miR-206 expression may be closely associated with the development of tumors. It has been reported that overexpression of miR-206 can decrease tumor cell viability, proliferation, migration, invasion and epithelial-to-mesenchymal transition, thus inhibiting the metastatic potential in breast cancer $(8,19)$, while miR-206 
knockdown promotes $\mathrm{CRC}$ promotion by activating $\mathrm{C}-\mathrm{C}$ motif chemokine ligand 2 (CCL2) (20) and upregulating C-X-C chemokine receptor type 4 and VEFG-A (14). However, the underlying molecular mechanism of how miR-206 regulates the progression of CRC requires further investigation.

Thus, the present study aimed to investigate whether miR-206 inhibits CRC progression by regulating the c-Met/AKT/GSK-3 pathway. The effects of miR-206 on proliferation, migration, and invasion of CRC cells were assessed via gain or loss of function of miR-206. Taken together, the results of the present study demonstrated that overexpression of miR-206 suppressed the proliferation, migration and invasion of CRC cells by targeting the c-Met/AKT/GSK-3 $\beta$ pathway.

\section{Materials and methods}

Cell culture and treatment. The human colonic cancer cell lines, HCT116 and SW480, were purchased from The Cell Bank of Type Culture Collection of Chinese Academy of Sciences. Cells were maintained in DMEM (Gibco; Thermo Fisher Scientific, Inc.) supplemented with $10 \%$ fetal bovine serum (FBS; Cytiva), at $37^{\circ} \mathrm{C}$ in $5 \% \mathrm{CO}_{2}$.

Reagents and transfection. miR-206 mimic, mimic negative control (mimic NC), miR-206 inhibitor, inhibitor NC, c-Met small interfering (si)RNA targeting c-Met (si-c-Met) and si-NC (scramble siRNA) were purchased from Guangzhou RiboBio Co., Ltd. The sequences of miR-206 mimic and inhibitor were as follows: miR-206 mimic, 5'-UGGAAUGUAAGGAAG UGUGUGG-3'; mimic NC, 5'-UUGUACUACACAAAAGUA CUG-3'; miR-206 inhibitor, 5'-CCACACACUUCCUUACAU UCCA-3'; and inhibitor NC, 5'-CAGUACUUUUGUGUAGUA CAA-3'. The sequences of si-c-Met and si-NC were as follows: si-c-Met sense, 5'-GGUGUUGUCUCAAUAUCAATT-3', and antisense, 5'-UUGAUAUUGAGACAACACCTT-3'; si-NC sense, 5'-UUCUCCGAACGUGUCACGUTT-3' and antisense, 5'-ACGUGACACGUUCGGAGAATT-3'. CRC cells were transfected with oligonucleotides using Lipofectamine ${ }^{\circledR} 2000$ reagent (Thermo Fisher Scientific, Inc.), according to the manufacturer's instructions. Briefly, CRC cells were seeded into 6 -well plates at a density of $1 \times 10^{5}$ cells $/ \mathrm{ml}$ and transfected with $50 \mathrm{nM}$ oligonucleotides or scrambled duplexes using transfection reagent at $37^{\circ} \mathrm{C}$ in a humidified incubator with $5 \% \mathrm{CO}_{2}$ for $48 \mathrm{~h}$. Transfection efficiency was assessed via reverse transcription-quantitative PCR or western blot analyses $48 \mathrm{~h}$ post-transfection.

$R T-q P C R$. Total RNA was extracted from CRC cells in each group using TRIzol reagent (Thermo Fisher Scientific, Inc.) and cDNA was synthesized using the One-Step miRNA RT kit (cat.no. 639503, Takara Bio, Inc.), at $37^{\circ} \mathrm{C}$ for $60 \mathrm{~min}$. miR-206 expression was detected and analysed using qPCR using SYBR Premix $^{\text {Ex }}$ Taq (cat. no. RR820A, Takara Bio, Inc.). U6 was used as the internal control to normalize relative miR-206 expression. The following primer sequences were used for qPCR: miR-206 RT primer, 5'-CTCAGCGGCTGTCGTGGACTG CGCGCTGCCGCTGAGCCACACAC-3'; miR-206 forward, 5'-GGCGGTGGAATGTAAGGAAG-3' and reverse, 5'-GGC TGTCGTGGACTGCG-3'; U6 RT primer, 5'-GTCGTATCC
AGTGCAGGGTCCGAGGTGCACTGGATACGACAAAAT ATGG-3'; and U6 forward, 5'-CTCGCTTCGGCAGCACA-3' and reverse, 5'-CTCGCTTCGGCAGCACA-3'. The thermocycling conditions were as follows: $95^{\circ} \mathrm{C}$ for $10 \mathrm{~min}$, followed by 40 cycles of amplification $\left(95^{\circ} \mathrm{C}\right.$ for $30 \mathrm{sec}, 58^{\circ} \mathrm{C}$ for $60 \mathrm{sec}$, $72^{\circ} \mathrm{C}$ for $90 \mathrm{sec}$ ), and a final extension step of $72^{\circ} \mathrm{C}$ for $5 \mathrm{~min}$. miRNA levels were quantified using the $2^{-\Delta \Delta \mathrm{Cq}}$ method (21).

Dual-luciferase reporter assay. The 3'-UTR of the human c-Met gene has a putative hsa-miR-206 binding sequence using the TargteScan database (release 7.2; http://www.targetscan. org/vert_72/). The luciferase reporter vector Pgl4Luc-RLuc (Addgene, Inc.) was used to establish a wild-type (WT) c-Met luciferase reporter plasmid or a mutant (MUT) c-Met luciferase reporter plasmid (Shanghai GenePharma Co., Ltd.). SW480 cells were subsequently co-transfected with miR-206 mimic (100 nM) or mimic NC and $200 \mathrm{ng}$ WT or MUT c-Met 3'-UTR luciferase reporter plasmid using Lipofectamine ${ }^{\circledR}$ 2000 reagent (Invitrogen; Thermo Fisher Scientific, Inc.). Following incubation for $48 \mathrm{~h}$ at $37^{\circ} \mathrm{C}$, relative luciferase activities were detected using a Dual-luciferase reporter assay system (Beijing Abace Biotech, Co., Ltd.). and normalized by using the ratio of firefly to Renilla luciferase activity.

MTT assay. HCT116 or SW480 cells were transfected with oligonucleotides (miR-206 mimic, mimic NC, si-c-MET or si-NC), with concentrations ranging from $50-100 \mathrm{nM}$. Following incubation for $48 \mathrm{~h}$ at $37^{\circ} \mathrm{C}$, cell viability was assessed via the MTT assay. Briefly, cells were seeded into 96-well microdilution plates at a density of $2 \times 10^{3}$ cells/well with DMEM containing 10\% FBS. MTT reagent (cat. no. C0009S; Beyotime Biotech, Co., Ltd.) was added on 3 consecutive days at a final concentration of $5 \mathrm{mg} / \mathrm{ml}$. Following the MTT incubation at $37^{\circ} \mathrm{C}$ for $4 \mathrm{~h}$, the purple formazan crystals were dissolved using $150 \mu \mathrm{l}$ DMSO and viability was subsequently analyzed at a wavelength of $570 \mathrm{~nm}$, using an Enzyme Immunoassay Analyzer (Bio-Rad Laboratories, Inc.). Cell viability was calculated and normalized to the respective $\mathrm{NC}$ group.

Cell migration and invasion assays. Cell migration and invasion were assessed via the Transwell assays, with or without Matrigel. For the invasion assay, Transwell membranes were precoated with $50 \mu \mathrm{l}$ diluted Matrigel (BD Biosciences) for $2 \mathrm{~h}$ at $37^{\circ} \mathrm{C}$. Following transfection, $6 \times 10^{4}$ cells were plated in the upper chambers of Transwell plates in $200 \mu 1$ serum-free DMEM medium, while $600 \mu 1$ cell-free DMEM medium supplemented with $10 \%$ FBS was plated in the lower chambers. Following incubation for $24 \mathrm{~h}$ at $37^{\circ} \mathrm{C}$, cells in the upper chambers were removed using a cotton swab. The invasive cells in the lower chambers were fixed with $100 \%$ pre-cold methanol for $10 \mathrm{~min}$ and stained with $0.1 \%$ crystal violet for $30 \mathrm{~min}$ at room temperature. For the migration assay, the same process was performed; however, Matrigel was not added in the upper chambers. Stained cells were counted in five randomly selected fields using a light microscope (Olympus Corporation; magnification, x200).

Western blotting. Transfected cells were collected and lysed using RIPA lysis buffer (Beyotime Institute of Biotech). 
A
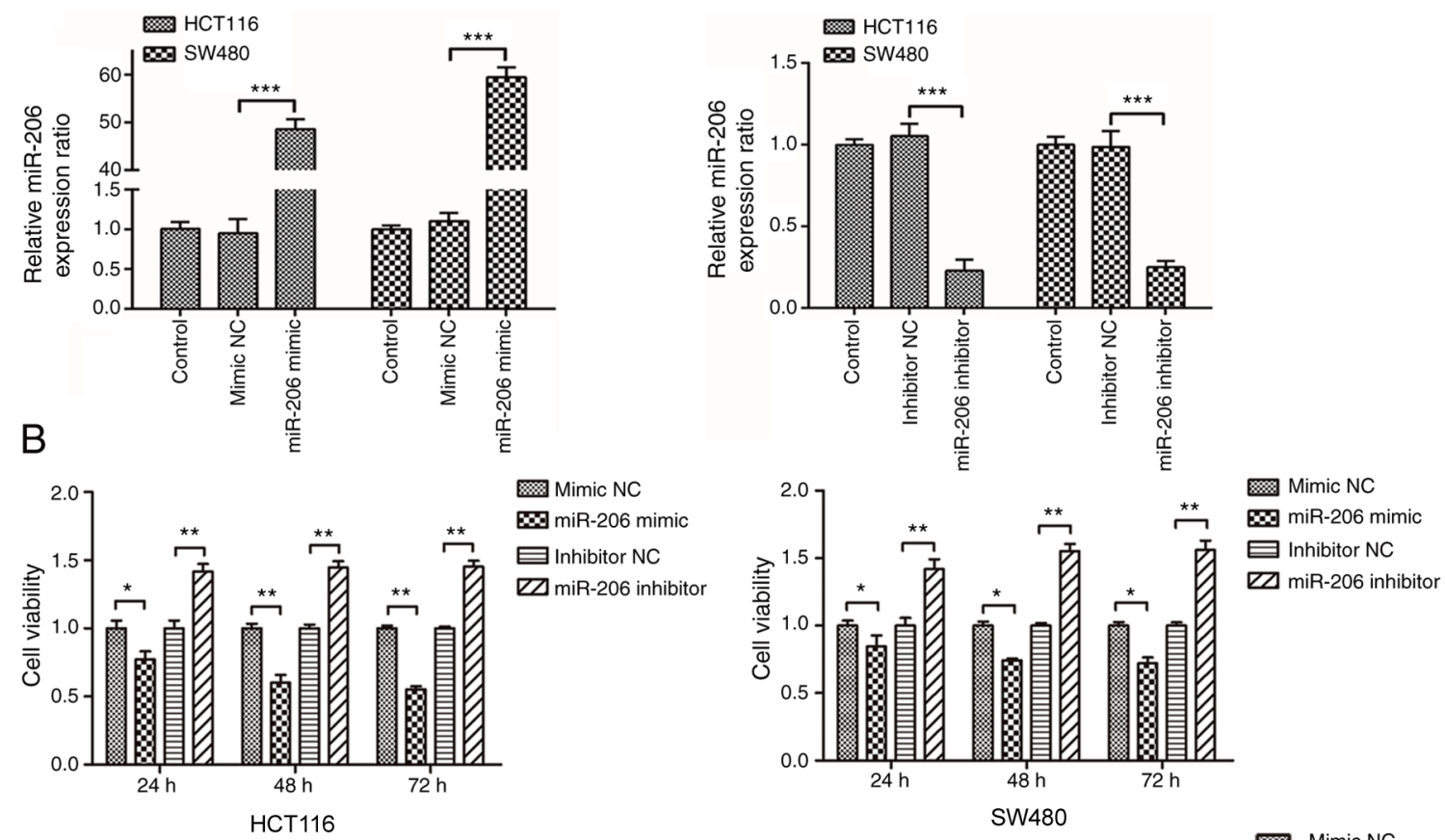

C
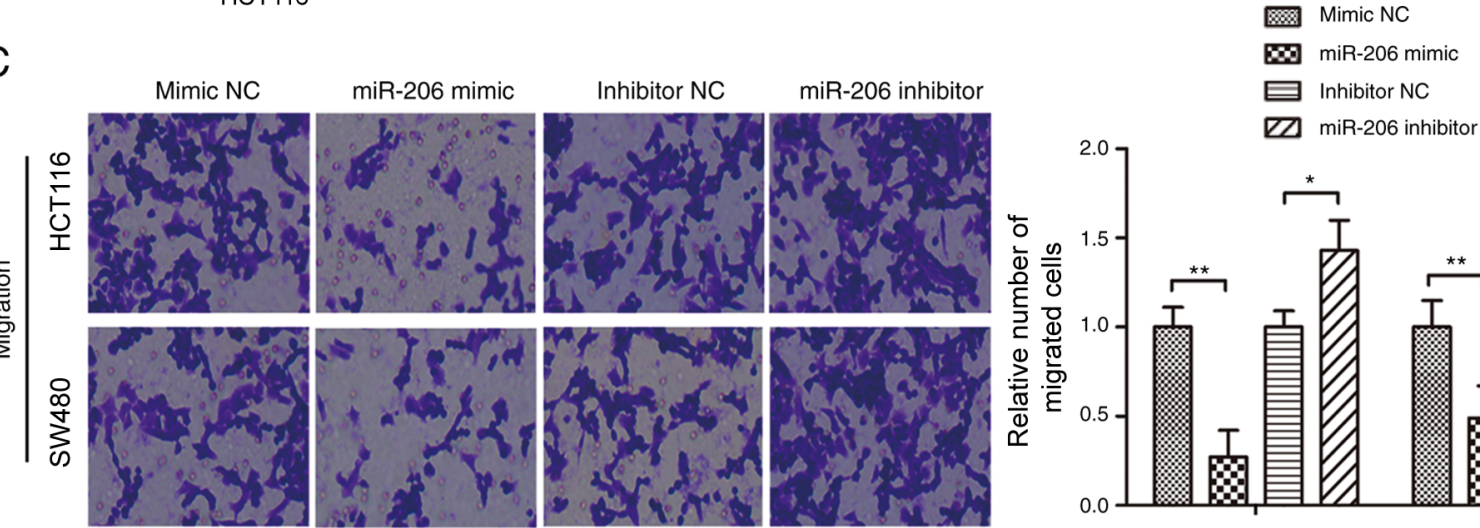

D
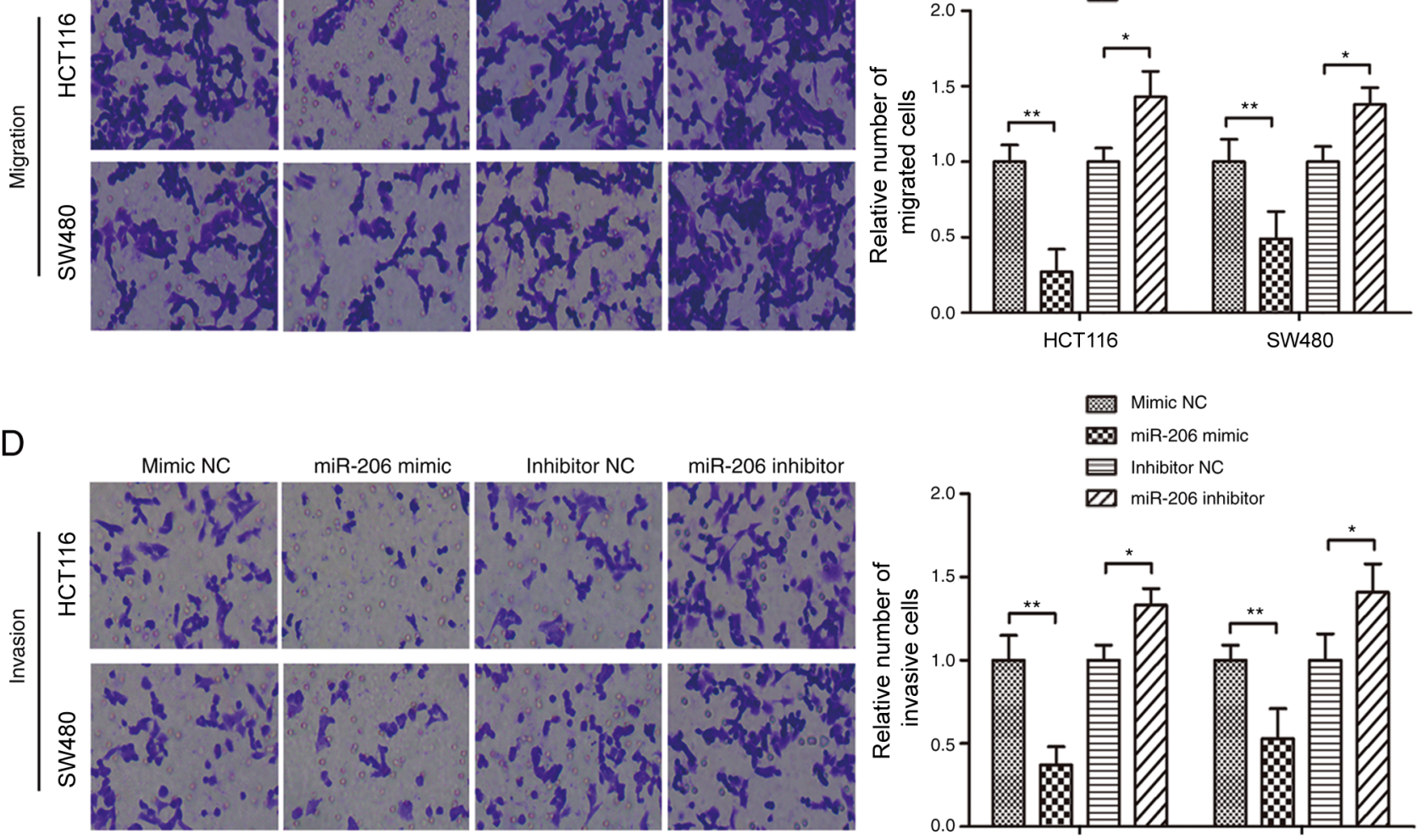

Mimic NC

$\mathbf{B}$ miR-206 mimic

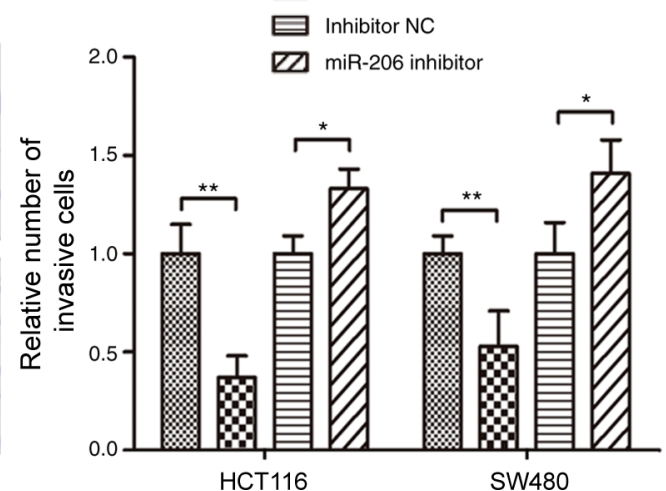

Figure 1. Effects of miR-206 on the proliferation, migration and invasion of colorectal cancer cells. (A) Reverse transcription-quantitative PCR analysis was performed to detect miR-206 expression in HCT116 and SW480 cells following transfection with miR-206 mimic or inhibitor for 48 h. (B) Viability of HCT116 and SW480 cells was assessed via the MTT assay following transfection with miR-206 mimic or miR-206 inhibitor. (C and D) Cell migratory and invasive abilities were assessed via Transwell assays. ${ }^{*} \mathrm{P}<0.05,{ }^{* *} \mathrm{P}<0.01,{ }^{* * *} \mathrm{P}<0.001 . \mathrm{miR}$, microRNA; NC, negative control.

Extracted total protein was quantified using the BCA protein assay kit (cat. no. P0012; Beyotime Institute of Biotech). A total of $25 \mu \mathrm{g}$ protein was separated via 8 or $10 \%$ SDS-PAGE and transferred onto PVDF membranes. The membranes were blocked with $5 \%$ skim milk for $1 \mathrm{~h}$ at room temperature and then incubated with primary antibodies against: AKT (1:1,000; cat. no. 9272; Cell Signaling Technology, Inc.), phosphorylated (p)-AKT (Ser473) (1:500; cat. no. 4060; Cell 


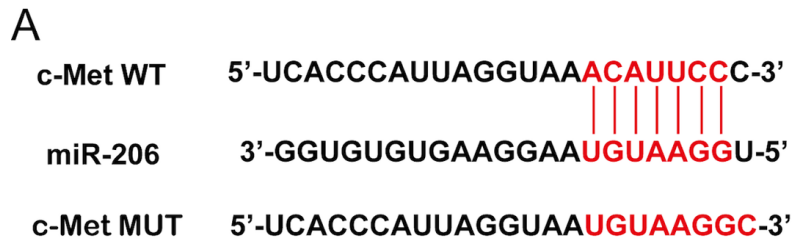

B

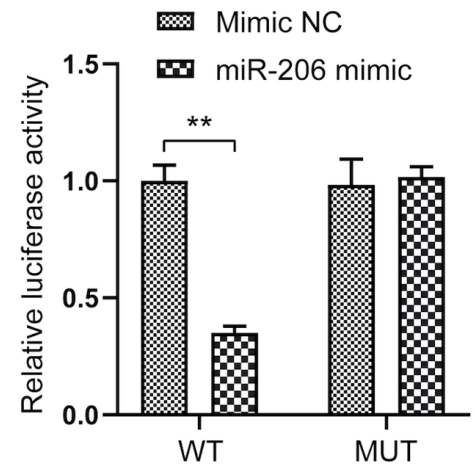

D

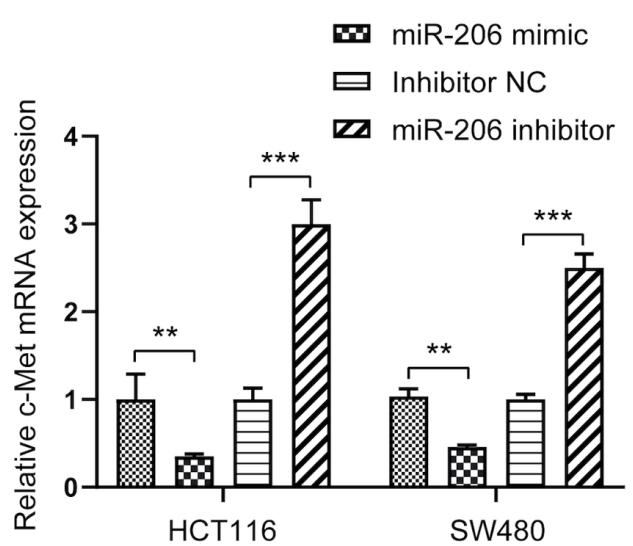

C

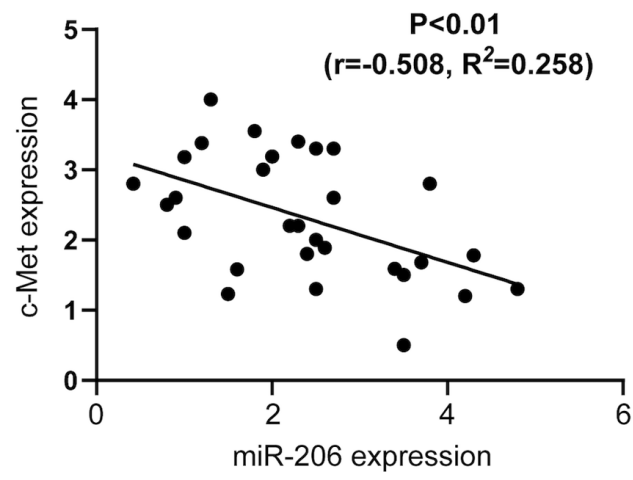

E

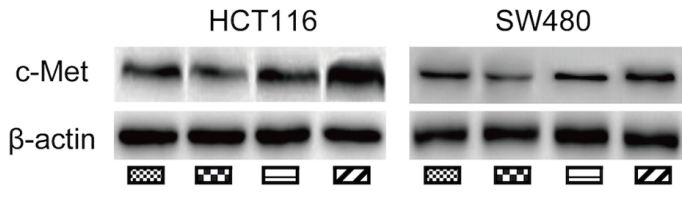

Mimic NC

Bit miR-206 mimic

曰 Inhibitor NC

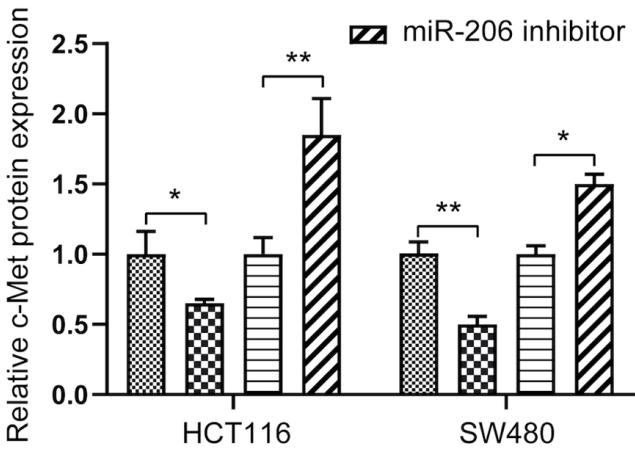

Figure 2. c-Met is a direct target of miR-206. (A) Complementary sequences of miR-206 binding site in WT c-Met 3'-UTR and MUT c-Met 3'-UTR (B) Luciferase activity was measured to assess the binding ability of miR-206 on the c-Met 3'-UTR WT or MUT in SW480 cells. (C) Spearman's correlation analysis was performed to determine the correlation between miR-206 and c-Met expression levels in SW480 cells. (D) mRNA and (E) protein expression levels of c-Met in HCT116 and SW480 cells were detected via reverse transcription-quantitative PCR and western blot analyses, respectively. "P $<0.05$, " $\mathrm{P}<0.01$, ${ }_{* * * *} \mathrm{P}<0.001$. miR, microRNA; WT, wild-type; UTR, untranslated region; MUT, mutant; NC, negative control.

Signaling Technology, Inc.), GSK-3 $\beta$ (1:1,000; cat. no. 12456; Cell Signaling Technology, Inc.), phosphorylated (p)-GSK-3 $\beta$ (Ser9) (1:500; cat. no. 5558; Cell Signaling Technology, Inc.), $\beta$-actin (1:1,000; cat. no. 4970; Cell Signaling Technology, Inc.) and c-Met (1:1,000; cat. no. ab216330; Abcam) overnight at $4^{\circ} \mathrm{C}$. Following the primary incubation, membranes were incubated with HRP-linked secondary antibodies (anti-mouse IgG, 1:10,000; cat. no. 7076; anti-rabbit IgG, 1:10,000, cat. no. 7074; Cell Signaling Technology, Inc.) for $1 \mathrm{~h}$ at room temperature. Immunoreactive bands were detected using Immobilon Forte Western HRP substrate reagents (EMD Millipore) and imaged using automatic chemiluminescence analyzer (Tanon Science and Technology Co., Ltd.). The gray value of target bands in each group was analyzed using ImageJ software (1.50d; National Institutes of Health).

Statistical analysis. Statistical analysis was performed using SPSS 22.0 software (IBM Corp.). All experiments were performed in triplicate and data are presented as the mean \pm standard deviation. Paired or unpaired Student's t-test were used to compare differences between two groups, while one-way ANOVA followed by Tukey's post hoc test were used to compare differences between multiple groups. Spearman's correlation analysis was performed to assess the correlation between miR-206 and c-Met. $\mathrm{P}<0.05$ was considered to indicate a statistically significant difference. 
A

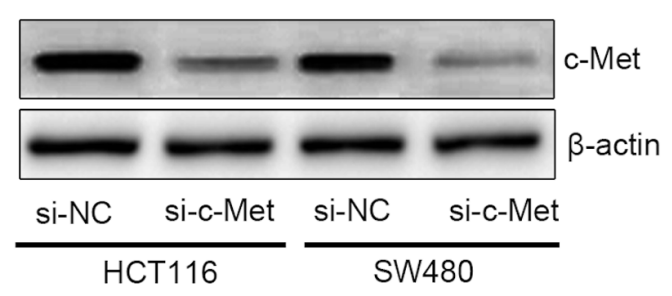

C
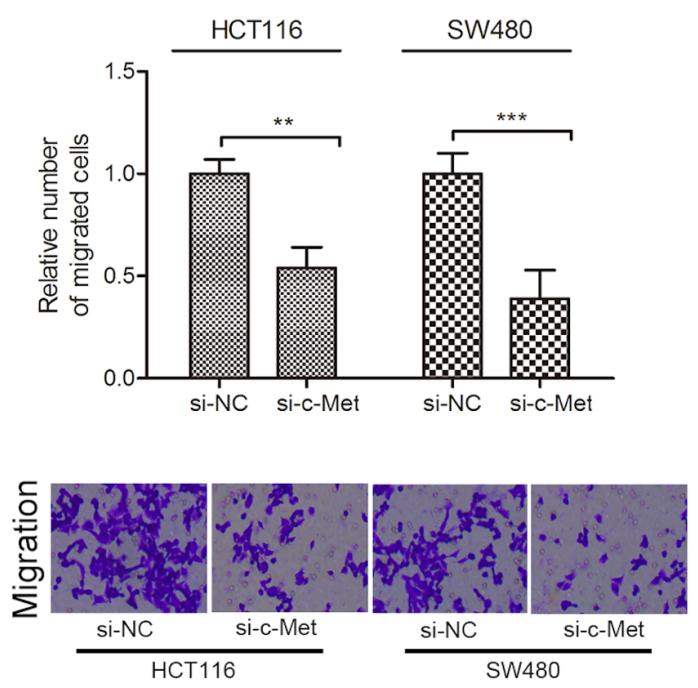

B

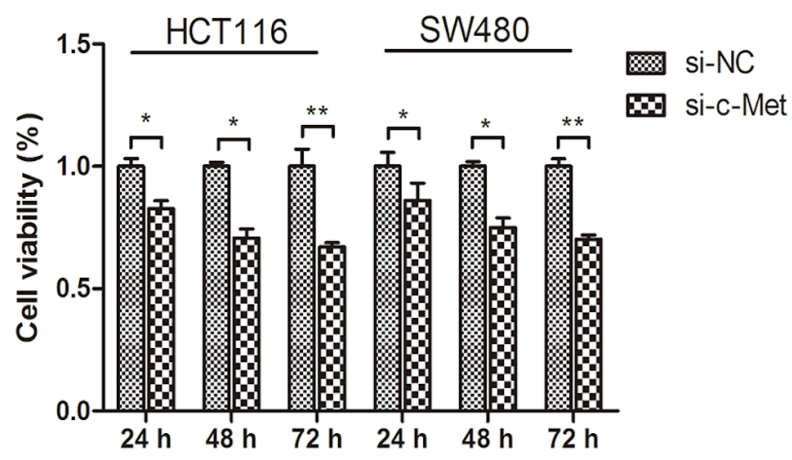

D
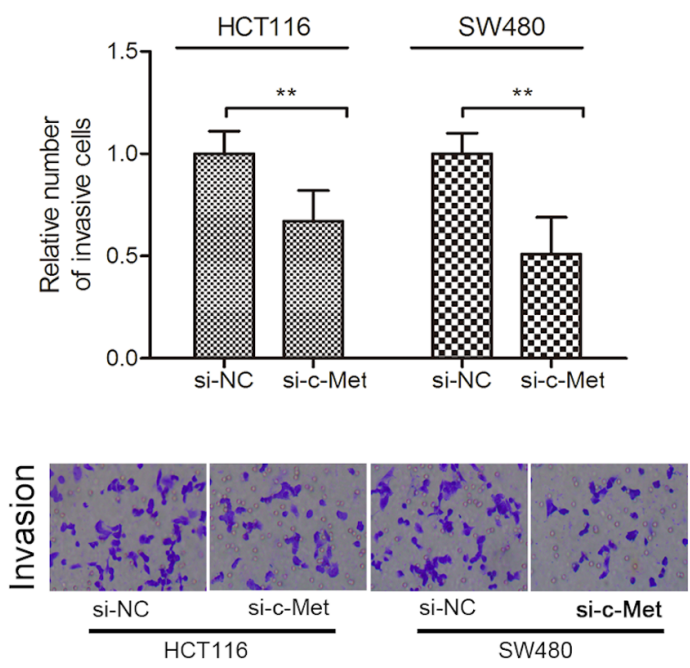

Figure 3. Effects of c-Met on the proliferation, migration and invasion of colorectal cancer cells. (A) Western blot analysis was performed to detect c-Met protein expression in HCT116 and SW480 cells following transfection with si-c-Met. (B) Cell viability was assessed via the MTT assay following transfection for 24, 48 and $72 \mathrm{~h}$. (C and D) Cell migratory and invasive abilities were assessed via Transwell assays. ${ }^{*} \mathrm{P}<0.05,{ }^{* *} \mathrm{P}<0.01,{ }^{* * * *} \mathrm{P}<0.001$. si, small interfering; $\mathrm{NC}$, negative control.

\section{Results}

miR-206 inhibits the proliferation, migration and invasion of CRC cells. As presented in Fig. 1A, miR-206 expression significantly increased in HCT116 and SW480 cells following transfection with miR-206 mimic $(\mathrm{P}<0.001)$, while transfection with miR-206 inhibitor significantly decreased miR-206 expression $(\mathrm{P}<0.001)$. In addition, overexpression of miR-206 significantly suppressed the proliferative, migratory and invasive abilities of CRC cells $(\mathrm{P}<0.05)$; however, transfection with miR-206 inhibitor promoted the proliferation, migration and invasion of cells (Fig. 1B-D).

$c$-Met is a direct target gene of $m i R-206$. The potential target genes of miR-206 were screened using the TargetScan Human database. c-Met was identified as one of the potential targets of miR-206. To further verify that c-Met was a direct target gene of miR-206, the fluorescent reporter vectors with WT or MUT 3'-UTR sequences of c-Met were co-transfected with miR-206 mimic (Fig. 2A). As presented in Fig. 2B, relative luciferase activity of the c-Met WT 3'-UTR vector significantly decreased $(\mathrm{P}<0.01)$, whereas relative luciferase activity of the c-Met MUT 3'-UTR vector was not affected following transfection with miR-206 mimic, suggesting that c-Met is direct target gene of miR-206. Furthermore, Spearman's correlation analysis demonstrated that c-Met expression was negatively correlated with miR-206 expression (Fig. 2C).

The present study investigated whether c-Met was involved in the miR-206-mediated effects in CRC. As expected, overexpression of miR-206 significantly decreased the mRNA and protein expression levels of c-Met in HCT116 and SW480 cells $(\mathrm{P}<0.05$ or $\mathrm{P}<0.01)$, the effects of which were reversed following transfection with miR-206 inhibitor (Fig. 2D and E).

Knockdown of c-Met inhibits the proliferation, migration and invasion of HCT116 and SW480 cells. As presented in Fig. 3A, c-Met protein expression significantly decreased in HCT116 and SW480 cells following transfection with si-c-Met. Knockdown of c-Met significantly decreased the viability, migration and invasion of CRC cells compared with the si-NC group $(\mathrm{P}<0.05$; Fig. 3B-D $)$.

miR-206-mediates the downregulation of c-Met and inhibits $A K T / G S K-3 \beta$ signaling. The expression levels of $\mathrm{p}-\mathrm{AKT}$ 


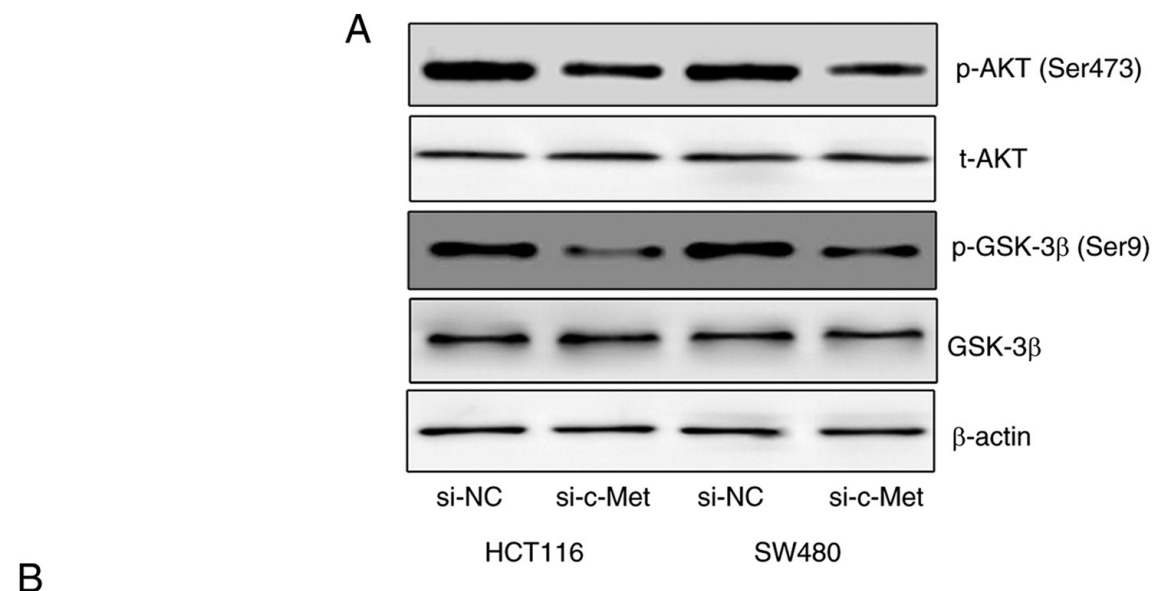

B
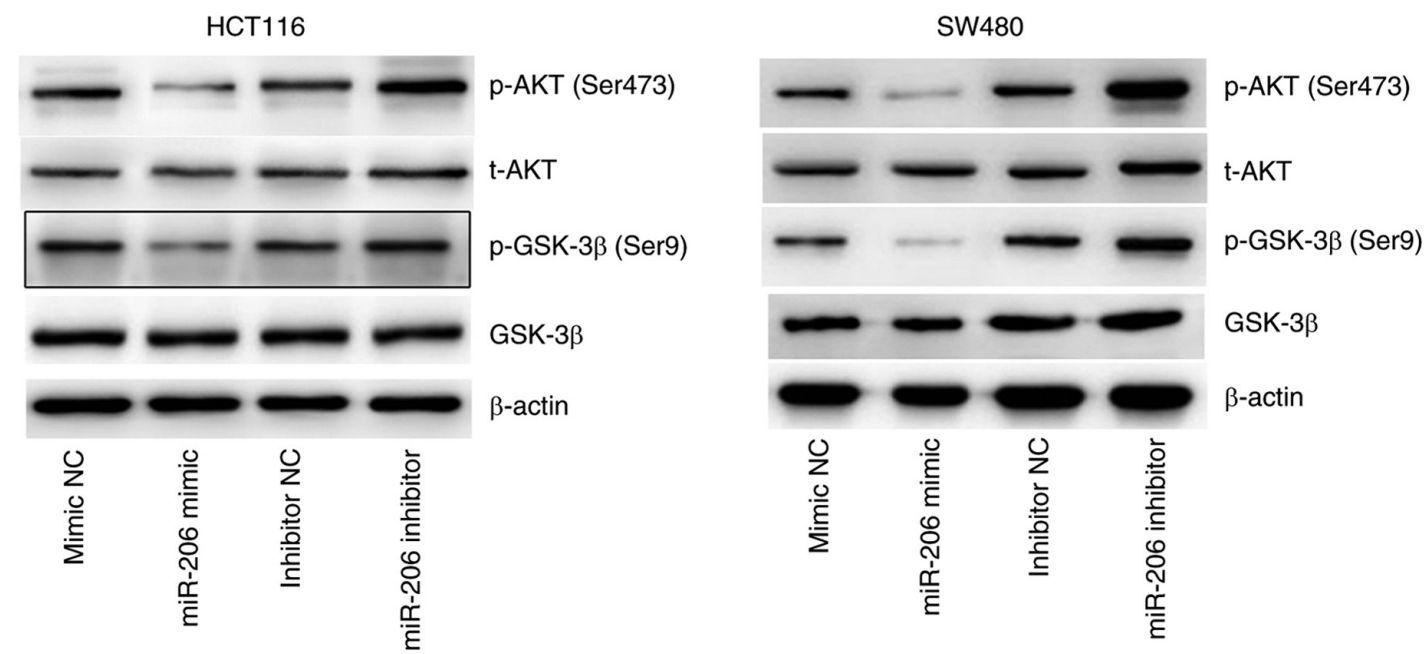

Figure 4. Effects of c-Met and miR-206 on the AKT/GSK-3 $\beta$ signaling pathway. (A) Western blot analysis was performed to detect protein expression levels of p-AKT and p-GSK-3 $\beta$ in HCT116 and SW480 cells transfected with si-c-Met. (B) Western blot analysis was performed to detect protein expression levels of p-AKT and p-GSK-3 $\beta$ in HCT116 and SW480 cells transfected with miR-206 mimic or inhibitor. miR, microRNA; p-, phosphorylated; si, small interfering; NC, negative control.

(Ser473) and p-GSK-3ß (Ser9) markedly decreased following inhibition of c-Met (Fig. 4A), suggesting that c-Met regulates the activation of AKT/GSK-3 $\beta$ signaling. In addition, overexpression of miR-206 was associated with decreased expression levels of p-AKT and p-GSK-3 $\beta$, the effects of which were reversed following transfection with miR-206 inhibitor (Fig. 4B). Taken together, these results suggest that miR-206 mediates downregulation of c-Met and inhibits AKT/GSK-3 $\beta$ signaling.

\section{Discussion}

The initiation of malignant tumors usually begins from dysregulation of the normal growth regulatory mechanism, as well as cells undergoing hyperproliferation, evading apoptosis, becoming invasive and ultimately acquiring a malignant phenotype (22). Aberrant expression of miRNAs is closely associated with the tumorigenesis and progression of tumor, including CRC. For example, it has been reported that miRNAs can act as proto-oncogenes, such as miR-346, or tumor suppressors, such as miR-187-3p, to regulate cell proliferation, apoptosis and differentiation (23). Previous studies have demonstrated that miR-206 is dysregulated in different types of human cancer, including colon (24), lung (10), prostate (15) and breast cancer (19), suggesting that miR-206 serves an important role in tumorigenesis. In addition, clinical research has reported that serum miR-206 expression significantly decreases in patients with CRC compared with healthy controls, and was confirmed to be an independent prognostic indicator for CRC, as patients with CRC with low miR-206 expression experience poor overall survival and disease-free survival than those with high miR-206 expression, suggesting that miR-206 may be a promising biomarker for the diagnosis and prognosis of CRC (25). However, the underlying molecular mechanism of miR-206 in regulating the progression of CRC remains unknown, although several researchers have suggested the repression of miR-206 on proliferation, migration, invasion (21) and angiogenesis (14).

Previous studies have reported that overexpression of miR-206 can inhibit CRC cell migration and invasion (26), as well as prostaglandin E2-induced CRC cell proliferation, migration and invasion by targeting transmembrane $4 \mathrm{~L}$ six family member 1 (27). In addition, miR-206 knockdown promotes drug resistance and decreases the apoptosis of HCT116/FR cells (28). The results of the present study demonstrated that overexpression of miR-206 suppressed the proliferation, migration and invasion of HCT116 and SW480 cells, the effects of which were reversed following miR-206 
knockdown, suggesting that miR-206 may be involved in the development of CRC by suppressing the proliferation, migration and invasion of CRC cells.

c-Met, also known as MET, acts as an oncogene and has been identified as a direct target of miR-206 (29), and has also been demonstrated to regulate proliferation, invasion and metastasis of tumor cells $(10,30)$. It has been reported that miR-206 suppresses the proliferation, migration and invasion of lung cancer cells by downregulating c-Met signaling $(31,32)$. c-Met upregulation has been observed in different types of human cancer, including CRC and exhibits oncogenic activity $(33,34)$. It has been demonstrated that specific inhibition of the STAT3/c-Met pathway can potentially neutralize the intrahepatic metastatic implantation and increase growth over a short-lived temporal window caused by radiofrequency ablation of healthy liver in an intrahepatic CRC mice model (35). A positive association between c-Met expression and tumor stages of CRC liver metastasis and lymph node metastasis has been suggested (36), indicating that c-Met expression may be a significant prognostic factor in CRC metastasis. In addition, a previous study revealed that overexpression of miR-206 and inhibition of the c-Met/ERK/Elk-1/HIF-1 $\alpha /$ VEGF-A pathway by CCL19 suppresses angiogenesis in CRC (37).

The results of the present study demonstrated that miR-206 expression was negatively correlated with c-Met expression in CRC cells, and identified that c-Met knockdown significantly inhibited the proliferation, migration and invasion of CRC cells. Taken together, these results suggest that miR-206 may regulate the progression of CRC cells by targeting c-Met. It has been reported that c-Met can mediate the activation of several intracellular signaling pathways, including the AKT/GSK-3 $\beta$, STAT3, SRC/FAK and MAPK/ERK pathways (38-40). Activation of these pathways results in the emergence of diverse cellular hallmarks of cancer, including cell proliferation, survival, inhibition of inflammation and apoptosis, migration, invasion and metastasis (41-43).

The present study investigated the expression levels of p-Akt and p-GSK-3 $\beta$ and demonstrated that c-Met knockdown significantly decreased the expression levels of these factors. Further investigation revealed that overexpression of miR-206 decreased the expression levels of p-Akt and p-GSK-3 $\beta$, the effects of which were reversed following miR-206 knockdown. Collectively, these results suggest that miR-206 may downregulate activity of the Akt/GSK-3 $\beta$ pathway by targeting c-Met, thus suppressing the proliferation, migration and invasion of $\mathrm{CRC}$ cells. Further research is required to confirm whether the effect of miR-206 on CRC cells can be reversed by specifically activating the Akt/GSK-3 $\beta$ pathway, thus providing further evidence to clarify the molecular mechanism of miR-206 in regulating the progression of CRC cells. In addition, whether miR-206 can regulate tumor growth and metastasis via the Akt/GSK-3 $\beta$ pathway requires further investigation.

In conclusion, the results of the present study demonstrated that miR-206 suppressed the proliferation, migration and invasion of CRC cells by targeting the c-Met/AKT/GSK-3 $\beta$ signaling pathway. These findings demonstrate the antitumor effects of miR-206 and its underlying molecular mechanism, which may aid in the development of more effective and promising therapies against CRC.

\section{Acknowledgements}

Not applicable.

\section{Funding}

No funding was received.

\section{Availability of data and materials}

The datasets used and/or analyzed during the present study are available from the corresponding author upon reasonable request.

\section{Authors' contributions}

JL performed the experiments and drafted the initial manuscript. YS performed the statistical analysis. HM and XL conceived and designed the experiments. All authors have read and approved the final manuscript.

\section{Ethics approval and consent to participate}

Not applicable.

\section{Patient consent for publication}

Not applicable.

\section{Competing interests}

The authors declare that they have no competing interests.

\section{References}

1. Bray F, Ferlay J, Soerjomataram I, Siegel RL, Torre LA and Jemal A: Global cancer statistics 2018: GLOBOCAN estimates of incidence and mortality worldwide for 36 cancers in 185 countries. CA Cancer J Clin 68: 394-424, 2018.

2. Zeng M, Zhu L, Li L and Kang C: miR-378 suppresses the proliferation, migration and invasion of colon cancer cells by inhibiting SDAD1. Cell Mol Biol Lett 22: 12, 2017.

3. Wang B, Liu G, Ding L, Zhao J and Lu Y: FOXA2 promotes the proliferation, migration and invasion, and epithelial mesenchymal transition in colon cancer. Exp Ther Med 16: 133-140, 2018.

4. Rupaimoole R, Calin GA, Lopez-Berestein G and Sood AK: miRNA deregulation in cancer cells and the tumor microenvironment. Cancer Discov 6: 235-246, 2016.

5. Ma W, Liu B, Li J, Jiang J, Zhou R, Huang L, Li X, He X and Zhou Q: MicroRNA-302c represses epithelial-mesenchymal transition and metastasis by targeting transcription factor AP-4 in colorectal cancer. Biomed Pharmacother 105: 670-676, 2018.

6. Dou C, Liu Z, Xu M, Jia Y, Wang Y, Li Q, Yang W, Zheng X, Tu K and Liu Q: miR-187-3p inhibits the metastasis and epithelial-mesenchymal transition of hepatocellular carcinoma by targeting S100A4. Cancer Lett 381: 380-390, 2016.

7. Tu K, Liu Z, Yao B, Han S and Yang W: MicroRNA-519a promotes tumor growth by targeting PTEN/PI3K/AKT signaling in hepatocellular carcinoma. Int J Oncol 48: 965-974, 2016.

8. Yin K, Yin W, Wang Y, Zhou L, Liu Y, Yang G, Wang J and Lu J: MiR-206 suppresses epithelial mesenchymal transition by targeting TGF- $\beta$ signaling in estrogen receptor positive breast cancer cells. Oncotarget 7: 24537-24548, 2016.

9. Xu X, Zhu Y, Liang Z, Li S, Xu X, Wang X, Wu J, Hu Z, Meng S, Liu B, et al: c-Met and CREB1 are involved in miR-433-mediated inhibition of the epithelial-mesenchymal transition in bladder cancer by regulating Akt/GSK-3beta/Snail signaling. Cell Death Dis 7: e2088, 2016. 
10. Chen QY, Jiao DM, Yan L, Wu YQ, Hu HZ, Song J, Yan J, Wu LJ, Xu LQ and Shi JG: Comprehensive gene and microRNA expression profiling reveals miR-206 inhibits MET in lung cancer metastasis. Mol Biosyst 11: 2290-2302, 2015.

11. Hwang HW and Mendell JT: MicroRNAs in cell proliferation, cell death, and tumorigenesis. Br J Cancer 96 Suppl: R40-R44, 2007.

12. Ma G, Wang Y, Li Y, Cui L, Zhao Y, Zhao B and Li K: MiR-206, a key modulator of skeletal muscle development and disease. Int J Biol Sci 11: 345-352, 2015.

13. Zhu H, He G, Wang Y, Hu Y, Zhang Z, Qian X and Wang Y: Long intergenic noncoding RNA 00707 promotes colorectal cancer cell proliferation and metastasis by sponging miR-206. Onco Targets Ther 12: 4331-4340, 2019.

14. Zheng X, Ma YF, Zhang XR, Li Y, Zhao HH and Han SG: Circ_0056618 promoted cell proliferation, migration and angiogenesis through sponging with miR-206 and upregulating CXCR4 and VEGF-A in colorectal cancer. Eur Rev Med Pharmacol Sci 24: 4190-4202, 2020

15. Wang Y, Xu H, Si L, Li Q, Zhu X, Yu T and Gang X: MiR-206 inhibits proliferation and migration of prostate cancer cells by targeting CXCL11. Prostate 78: 479-490, 2018.

16. Yang N, Wang L, Liu J, Liu L, Huang J, Chen X and Luo Z: MicroRNA-206 regulates the epithelial-mesenchymal transition and inhibits the invasion and metastasis of prostate cancer cells by targeting Annexin A2. Oncol Lett 15: 8295-8302, 2018.

17. Liao M and Peng L: MiR-206 may suppress non-small lung cancer metastasis by targeting CORO1C. Cell Mol Biol Lett 25: 22,2020

18. Fan C, Liu N, Zheng D, Du J and Wang K: MicroRNA-206 inhibits metastasis of triple-negative breast cancer by targeting transmembrane 4 L6 family member 1 . Cancer Manag Res 11: 6755-6764, 2019.

19. Fu Y, Shao ZM, He QZ, Jiang BQ, Wu Y and Zhuang ZG: Hsa-miR-206 represses the proliferation and invasion of breast cancer cells by targeting Cx43. Eur Rev Med Pharmacol Sci 19: 2091-2104, 2015

20. Shengnan J, Dafei X, Hua J, Sunfu F, Xiaowei W and Liang X Long non-coding RNA HOTAIR as a competitive endogenous RNA to sponge miR-206 to promote colorectal cancer progression by activating CCL2. J Cancer 11: 4431-4441, 2020.

21. Livak KJ and Schmittgen TD: Analysis of relative gene expression data using real-time quantitative PCR and the 2(-Delta Delta C(T)) method. Methods 25: 402-408, 2001.

22. Calin GA and Croce CM: MicroRNA signatures in human cancers. Nat Rev Cancer 6: 857-866, 2006.

23. Pan JY, Sun CC, Bi ZY, Chen ZL, Li SJ, Li QQ, Wang YX, Bi YY and Li DJ: miR-206/133b cluster: A weapon against lung cancer? Mol Ther Nucleic Acids 8: 442-449, 2017.

24. Wang XW, Xi XQ, Wu J, Wan YY, Hui HX and Cao XF: MicroRNA-206 attenuates tumor proliferation and migration involving the downregulation of NOTCH3 in colorectal cancer. Oncol Rep 33: 1402-1410, 2015.

25. Liu X, Zheng W, Zhang X, Dong M and Sun G: The diagnostic and prognostic value of serum miR-206 in colorectal cancer. Int J Clin Exp Pathol 10: 7528-7533, 2017.

26. Sun P, Sun D, Wang X, Liu T, Ma Z and Duan L: miR-206 is an independent prognostic factor and inhibits tumor invasion and migration in colorectal cancer. Cancer Biomark 15: 391-396, 2015.

27. Park YR, Seo SY, Kim SL, Zhu SM, Chun S, Oh JM, Lee MR, Kim SH, Kim IH, Lee SO, et al: MiRNA-206 suppresses PGE2-induced colorectal cancer cell proliferation, migration, and invasion by targetting TM4SF1. Biosci Rep 38: BSR20180664, 2018.
28. Meng $X$ and Fu R: miR-206 regulates 5-FU resistance by targeting Bcl-2 in colon cancer cells. Onco Targets Ther 11: $1757-1765,2018$

29. Ren XL, He GY, Li XM, Men H, Yi LZ, Lu GF, Xin SN, Wu PX, Li YL, Liao WT, et al: MicroRNA-206 functions as a tumor suppressor in colorectal cancer by targeting FMNL2. J Cancer Res Clin Oncol 142: 581-592, 2016.

30. Dai C, Xie Y, Zhuang X and Yuan Z: MiR-206 inhibits epithelial ovarian cancer cells growth and invasion via blocking c-Met/AKT/mTOR signaling pathway. Biomed Pharmacother 104: 763-770, 2018.

31. Mataki H, Seki N, Chiyomaru T, Enokida H, Goto Y, Kumamoto T, Machida K, Mizuno K, Nakagawa M and Inoue H: Tumor-suppressive microRNA-206 as a dual inhibitor of MET and EGFR oncogenic signaling in lung squamous cell carcinoma. Int J Oncol 46: 1039-1050, 2015.

32. Chen X, Tong ZK, Zhou JY, Yao YK, Zhang SM and Zhou JY: MicroRNA-206 inhibits the viability and migration of human lung adenocarcinoma cells partly by targeting MET. Oncol Lett 12: 1171-1177, 2016.

33. Raghav K, Bailey AM, Loree JM, Kopetz S, Holla V, Yap TA, Wang F, Chen K, Salgia R and Hong D: Untying the gordion knot of targeting MET in cancer. Cancer Treat Rev 66: 95-103, 2018.

34. Zhao Y, Tao Q, Li S, Zheng P, Liu J and Liang X: Both endogenous and exogenous miR-139-5p inhibit Fusobacterium nucleatum-related colorectal cancer development. Eur J Pharmacol 888: 173459, 2020.

35. Liao H, Ahmed M, Markezana A, Zeng G, Stechele M, Galun E and Goldberg SN: Thermal ablation induces transitory metastatic growth by means of the STAT3/c-Met molecular pathway in an intrahepatic colorectal cancer mouse model. Radiology 294: 464-472, 2020

36. Yao JF, Li XJ, Yan LK, He S, Zheng JB, Wang XR, Zhou PH, Zhang L, Wei GB and Sun XJ: Role of HGF/c-Met in the treatment of colorectal cancer with liver metastasis. J Biochem Mol Toxicol 33: e22316, 2019.

37. Xu Z, Zhu C, Chen C, Zong Y, Feng H, Liu D, Feng W, Zhao J and Lu A: CCL19 suppresses angiogenesis through promoting miR-206 and inhibiting Met/ERK/Elk-1/HIF-1 $\alpha /$ VEGF-A pathway in colorectal cancer. Cell Death Dis 9: 974, 2018.

38. Gherardi E, Birchmeier W, Birchmeier C and Vande Woude G: Targeting MET in cancer: Rationale and progress. Nat Rev Cancer 12: 89-103, 2012.

39. Viticchiè G and Muller PAJ: c-Met and other cell surface molecules: Interaction, activation and functional consequences. Biomedicines 3: 46-70, 2015.

40. Yamaoka T, Kusumoto S, Ando K, Ohba M and Ohmori T: Receptor tyrosine kinase-targeted cancer therapy. Int J Mol Sci 19: 3491, 2018.

41. Organ SL and Tsao MS: An overview of the c-MET signaling pathway. Ther Adv Med Oncol 3 (Suppl 1): S7-S19, 2011.

42. Comoglio PM, Trusolino L and Boccaccio C: Known and novel roles of the MET oncogene in cancer: A coherent approach to targeted therapy. Nat Rev Cancer 18: 341-358, 2018.

43. Lu Z, Song N, Shen B, Xu X, Fang Y, Shi Y, Ning Y, Hu J, Dai Y, Ding X, et al: Syndecan-1 shedding inhibition to protect against ischemic acute kidney injury through HGF target signaling pathway. Transplantation 102: e331-e344, 2018.

This work is licensed under a Creative Commons Attribution-NonCommercial-NoDerivatives 4.0 International (CC BY-NC-ND 4.0) License. 